\title{
Revisiting organizational interpretation and three types of uncertainty
}

\author{
Sund, Kristian J.
}

Published in:

International Journal of Organizational Analysis

DOI:

10.1108/IJOA-06-2013-0686

\section{Publication date:}

2015

\section{Document Version}

Early version, also known as pre-print

Citation for published version (APA):

Sund, K. J. (2015). Revisiting organizational interpretation and three types of uncertainty. International Journal of Organizational Analysis, 23(4), 588-605. https://doi.org/10.1108/IJOA-06-2013-0686

\section{General rights}

Copyright and moral rights for the publications made accessible in the public portal are retained by the authors and/or other copyright owners and it is a condition of accessing publications that users recognise and abide by the legal requirements associated with these rights.

- Users may download and print one copy of any publication from the public portal for the purpose of private study or research.

- You may not further distribute the material or use it for any profit-making activity or commercial gain.

- You may freely distribute the URL identifying the publication in the public portal.

Take down policy

If you believe that this document breaches copyright please contact rucforsk@kb.dk providing details, and we will remove access to the work immediately and investigate your claim. 


\title{
REVISITING ORGANIZATIONAL INTERPRETATION \\ AND THREE TYPES OF UNCERTAINTY
}

\author{
Dr. Kristian J. Sund \\ PLEASE CITE AS:
}

Sund, K. J. (2015). Revisiting organizational interpretation and three types of uncertainty. International Journal of Organizational Analysis, 23(4), 588-605.

Full text in published version available here:

http://www.emeraldinsight.com/doi/abs/10.1108/IJOA-06-2013-0686

Roskilde University

Building 44.2

Universitetsvej 1

4000 Roskilde

Denmark

Email: sund@ruc.dk 


\title{
REVISITING ORGANIZATIONAL INTERPRETATION AND THREE TYPES OF UNCERTAINTY
}

\begin{abstract}

\section{Purpose}

The aim of this paper is to move towards a holistic model of organizational interpretation under uncertainty. This paper makes a series of novel conceptual propositions regarding the associations between state, effect and response uncertainty, and the organizational interpretation process.
\end{abstract}

\section{Methodology}

This conceptual paper extends existing conceptual work by distinguishing between general and issue-specific scanning and linking the interpretation process to three different types of perceived uncertainty: state, effect and response uncertainty.

\section{Findings}

It is proposed that environmental scanning leads to lower state and effect uncertainty, i.e. less uncertainty regarding the estimation of probabilities of events occurring in the external environment of the organization and of their consequences. It is further proposed that scanning leads to higher levels of perceived control over events and that the actual interpretation of events, in opportunity/threat terms, drives irregular issue-specific scanning and organizational reactions to such events.

\section{Research implications}

The paper suggests a way to test links between organizational interpretation and uncertainty that might help explain and untangle some of the conflicting empirical results found in the extant literature. The paper illustrates how the literature could benefit from re-conceptualizing the perceived environmental uncertainty construct to take into account different types of uncertainty.

\section{Practical implications}

For practitioners this paper emphasizes the importance of environmental scanning and how scanning practices can lead to general alertness, to more positive event interpretations, and how interpretations form responses to opportunities in the environment.

\section{Originality}

This paper extends on existing work by linking the interpretation process to three different types of uncertainty (state, effect and response uncertainty) with several novel and testable propositions. The paper also differentiates clearly general (regular) scanning from issue-specific 
(irregular) scanning. Finally, the paper provides a unifying view, piecing together in one picture elements that have so far been dispersed in the literature.

\section{Keywords:}

Perceived environmental uncertainty; scanning; interpretation; cognition; learning

\section{Category:}

Conceptual paper 


\section{Introduction}

An organization's ability to acquire, process, interpret and apply information about its external environment is considered to be major sources of competitive advantage (Weick et al, 2005; Zahra and George, 2002). This is particularly the case in turbulent environments (Lichtenthaler, 2009). Daft and Weick (1984) provide a popular description of the organizational process of interpretation and learning, whereby organizations scan the environment for information, which it then interprets, before acting on these interpretations. This process of organizational interpretation is carried out under conditions of uncertainty (Milliken 1990). Whilst there is ample evidence in existing literature that such organizational interpretation is important, there is much less evidence concerning the nature of the links between the various steps in this process, or between these steps and perceived uncertainty. This paper therefore develops a series of proposals regarding these links.

The environment is the source of both opportunities and threats for the organization (Jackson and Dutton, 1988) and organizational members perceive the environment and act in response to what they perceive. Although human beings carry out the actual interpretation of individual external events, organizations build systems and memories based on past processed information. Organizations also learn from their actions, as these actions are in turn analyzed and their effects collectively interpreted (Weick et al., 2005). Individual employees may come and go, but certain norms, cognitive maps and organizational knowledge are standardized, stored and preserved over time. Thus, the organization is capable of interpreting as a system. However, this is typically done under conditions of relative uncertainty with which executives must cope (Lawrence and 
Lorsch, 1967). Milliken (1987) suggests that organizations face three types of uncertainty when interpreting external issues. The first she refers to as state uncertainty, whereby managers find it difficult to assign probabilities to the occurrence of events. The second type of uncertainty is effect uncertainty, whereby managers are unable to assess what the effects of a future state of the environment will be on their organization. The third type of uncertainty is response uncertainty, whereby managers are uncertain as to possible responses to an environmental change, and how effective these will be.

Three problems face the scholar interested in the interpretation-uncertainty links. Firstly, conceptualizations and empirical evidence for the links are highly fragmented, with no single study painting a complete picture of the process of organizational interpretation and the links with multiple types of uncertainty. Secondly, several links within this process remain unexplored altogether. For example we know little about the influence of interpretations, and more generally of perceptions of the environment, on information search and subsequent organizational actions (Nag and Gioia, 2012). Very recent research suggests that environmental scanning in this context is not just an information and knowledge-acquisition activity, but actually shapes and amplifies information for subsequent knowledge use (Nag and Gioia, 2012; Sund, 2013). Thirdly, existing studies of the link between, for instance, scanning and uncertainty, are far from unanimous in their conclusions (Weick, 2002). Specifically, relatively little and sometimes contradictory evidence exists concerning the links between scanning, interpretation, state and effect uncertainty and little is known about the specifics of how issue-specific uncertainty affects actions. 
The mechanisms of the organizational interpretation process have thus not yet been fully explored and it is this lack of theory development that this paper attempts to remedy. In this paper it is argued that some of the conflicting empirical results found in the literature can be better explained by differentiating between two types of scanning, general and issue-specific, and by adopting a multidimensional view of perceived uncertainty (Milliken, 1987). In particular it is argued that general information seeking affects the interpretation of environmental issues, which in turn affects organizational responses. It is further argued that whilst scanning reduces state and effect uncertainty, response uncertainty negatively influences the level of organizational response to a given issue. The paper is a response to recent calls for more conceptual work on perceived uncertainty and sensemaking in general (Ashill and Jobber, 2010; Pandza and Thorpe, 2009), and on the links between information seeking, interpretation and uncertainty in particular (Anderson and Nichols, 2007; Suh et al., 2004; Sund, 2013).

\section{The Interpretation Process}

Executives' cognitive frameworks, or knowledge structures, serve as a way to organize knowledge about an information environment and enable some form of interpretation of information signals from that environment. Such frameworks direct both attention and interpretation (Dane, 2013), and help explain differences in how organizations react in response to information signals (Marcel et al., 2010). The individual manager has thus been referred to as an information worker (McCall and Kaplan, 1985) and organizations as information processing, or interpretation systems (Daft and Weick, 1984; Galbraith, 1974). In fact, organization and 
sensemaking are so intimately linked that it may be said that organization actually emerges through sensemaking, as people organize to make sense of equivocal information and join to act on that information (Weick et al., 2005). The three step interpretation process proposed by Daft and Weick (1984) suggests that organizations scan the environment and collect data, which is later analyzed and interpreted, thereby giving meaning to the data. Finally, actions are taken which result in organizational learning.

\section{Scanning}

Scanning is defined as the deliberate act of seeking information about events and relationships in the outside environment (Fahey and King, 1977). Scanning aims to recognize environmental changes (Sutcliffe, 1994), to improve the match between the objective environment and the manager's or organization's perception of that environment (Bourgeois, 1985), as well as to correctly assign probabilities to the occurrence of potential changes or events (Milliken, 1990). Recent studies have shed new light on the importance of scanning as a strategic capability with the ability to increase absorptive capacity, i.e. the ability of an organization to recognize, assimilate and apply valuable knowledge from external sources (Danneels, 2008).

Due mainly to scarcity of time, scanning is often done selectively across sub-sectors of the environment (Boyd and Fulk, 1996; Daft et al., 1988; Garg et al., 2003), such that the focus of scanning differs from one organization to another (Hambrick, 1982). Furthermore, organizations exhibit varying levels of scanning and use various methods of scanning (Beal, 2000; Fahey and King, 1977; Lang, et al., 1997; Sutcliffe, 1994). Scanning can for instance be both regular and 
irregular (Fahey and King, 1977; Huber, 1991). If knowledge structures are used to interpret change, then scanning serves to add to and enrich the knowledge structure content, whether at the individual, group or organization level. When measured, scanning is sometimes divided into scanning scope and scanning frequency, the former referring to the areas of the environment scanned and the latter to the frequency of use of various scanning mechanisms.

\section{Interpretation}

Organizational interpretation can be defined as the process of giving data meaning, or of translating external events into a shared understanding amongst organizational members. It is during this crucial phase that cognitive frameworks or mental maps play an important role. Narrative processes make it possible for groups of executives to make sense of and categorize events, thereby creating shared knowledge frameworks (Garud et al., 2011). Empirical studies thus suggest that executives use their collective knowledge and mental maps to label and categorize events (Garud et al., 2011; Thomas et al., 1993; Weick et al., 2005). Acts of categorization are a form of pattern recognition; i.e. a perception of similarities and differences, and how a given event is categorized by the organization is a part of, and will obviously affect, the interpretation itself.

Studies of cognition and interpretation have examined the likely factors affecting this process, and the possible origins of the underlying knowledge structures, including strategy (Thomas and McDaniel, 1990) and strategic type (Citrin et al., 2007), market orientation (Qiu, 2008), degree of diversification (Ginsberg, 1989), organization culture (Harris, 1994), industry velocity 
(Nadkarni and Barr, 2008), dynamism (Garg et al., 2003), cognitive motivation (Anderson, 2008) and a host of other organizational, team or individual level factors.

The event categorization the most commonly mentioned and investigated in the literature is the categorization of an event as a potential threat or opportunity to the organization. It has been suggested that there are three dimensions to this threat/opportunity categorization: (1) an evaluation of the event by managers in negative or positive terms, (2) an estimation by managers of potential losses or gains as a result of the event, and (3) a consideration of the controllability by the organization (Barr, 1998; Jackson and Dutton, 1988; Thomas et al., 1993; Thomas and McDaniel, 1990). Although individual members of the top management tend to have a large influence over the labeling of strategic issues, labels and categorizations are created during a social process of collective interpretation, through the use of "language to share perceptions among [managers who] gradually define or create meaning through discussion, groping, trial and error, and sounding out" (Huber and Daft, 1987, p.151). These labels are shared with the organization and ultimately influence the organizational actions taken in response to the issue (Julian and Ofori-Dankwa, 2008; Thomas et al., 1993).

\section{Action}

The final stage of the interpretation process involves organizational actions. It was labeled "learning" by Daft and Weick (1984), but the learning involves a new response or action based on the interpretation. The learning effect thus refers to the discovering and interpretation of new action-outcome relationships. The action phase leads to the accumulation of new knowledge and 
information which is in turn interpreted by the organization, leading to a feedback loop. Organizational actions can be changes of a strategic nature, of a competitive nature or of a structural nature (Dutton and Duncan, 1987; Ginsberg, 1988; Thomas et al., 1993) and recent studies point to interpretative learning mechanisms being positively linked to strategic innovation capacity (Berghman et al., 2013). As previously mentioned, the particular organizational action is intimately linked to the interpretation given to the environmental change (Barr, 1998). Thus, the particular interpretation given to an event will determine what actions will be taken, as will past experiences, given that these past experiences, and past learning, to some extent constrain the organization's repertoire of actions.

\section{Perceived Environmental Uncertainty}

Environmental uncertainty has for a long time been a central concept and variable in the study of organizations. This uncertainty has been considered by some an objective property of the environment, by others a perceptual phenomenon, such that the uncertainty is in the eye of the beholder (Milliken, 1987). As a result, estimations of environmental uncertainty have been carried out using either objective archival measures or subjective perceptual measures (see for example Boyd, Dess, and Rasheed, 1993, or Kreiser and Marino, 2002, for more detailed reviews of various measures). When the environmental uncertainty is viewed as an objective property of the environment, it is typically done using constructs that deal with particular attributes of the environment such as instability, rate of change, munificence, and complexity (Bourgeois, 1985). These objective measures can be estimated using archival time series data. Perceptual measures, on the other hand, generally depend on survey-based self-reported data, which many researchers 
have argued are more relevant, as it is likely to be managers' perceptions, rather than any objective reality that influence decision making (Ashill and Jobber, 2010; Doty et al., 2006; Downey and Slocum, 1975). A manager's perception of environmental uncertainty may change quite rapidly (Buchko, 1994), something objective measures may not pick up. Not surprisingly, early studies trying to compare objective and perceptual measures have yielded mixed results (Buchko, 1994; Downey et al., 1975; Tosi et al., 1973). Objective environmental uncertainty and perceived environmental uncertainty are in reality two very different constructs, despite sometimes being used interchangeably in the literature (Doty et al., 2006).

The measurement of subjective, perceived environmental uncertainty has been carried out using many different questionnaire instruments. These usually divide the environment into sectors, such as suppliers, competitors, customers, government and so forth. Respondents are then asked to rate the predictability of changes in each sector. Early studies of perceived uncertainty revealed that the most commonly used instruments are not necessarily correlated (Downey et al., 1975), most probably because they may not be measuring the same underlying construct (Milliken, 1987). Furthermore, there are demonstrated problems of validity and reliability for many of these instruments. For example, both the Lawrence and Lorsch (1967) scale, and the Duncan (1972) scale have been found to lack reliability (Downey and Slocum, 1975; Tosi et al., 1973). Miles and Snow (1978) proposed a widely used instrument with 22 items across six external environmental components: suppliers, competitors, customers, financial markets, government and unions. The various environmental components are equally weighted in their instrument, a fact which has been criticized, since for any particular organization, at any 
particular point in time, the strategic importance of the various components are likely to be unequal (Daft et al., 1988).

Despite the measurement problems, perceived environmental uncertainty continues to be a key construct within organizational research. However, whilst it has long been acknowledged that the environment is both complex and ambiguous (Starbuck and Milliken, 1988), as well as a source of uncertainty, the relationship between such uncertainty and the sensemaking or interpretation processes taking place within the organization remains underexplored and deserves further attention (Ashill and Jobber, 2010). If uncertainty is in fact omnipresent when organizations attempt to interpret signals from the environment, ignoring its effects on the interpretation process seems a serious omission. Rather than simply acting as a form of background noise perceived uncertainty is likely to accompany, influence and be influenced by, every step of the interpretation process.

An important step in trying to understand the role of uncertainty in the interpretive process of organizations was made by Milliken (1987), who proposed that perceived environmental uncertainty could be broken down into three types: state, effect and response uncertainty. She proposed in a later paper that these three types are related to the interpretation process such that the three types of uncertainty may reflect the three phases of the interpretation process outlined earlier (Milliken, 1990). Unfortunately, despite much attention having been given to both the interpretation process and the three types of perceived uncertainty individually, little has been done to extend the idea of bringing the two together conceptually. Milliken's $(1987,1990)$ work 
is thus frequently cited in the literature but only a small handful of papers have ever produced any theory about, or empirically tested for, her three types of uncertainty.

Milliken (1987) suggests that not only may environmental uncertainty arise from any of the various sub-sectors of the environment, but it may in fact arise in three distinct forms. The first she referred to as state uncertainty, which is the lack of predictability concerning environmental change. She suggests that this type of uncertainty is conceptually closest to the common conception of perceived environmental uncertainty. The executive is uncertain as to the probability of particular events or changes taking place. Thus, he or she finds the environment or portions of it to be unpredictable. An example of this kind of uncertainty would be the uncertainty associated with a potential competitor entering the market or not.

The second type of uncertainty is effect uncertainty, which refers to the inability of the executive to assess what the effects of a future state of the environment will be on their organization. This type of uncertainty therefore concerns cause-effect relationships and understanding whether an event will affect the organization and how deeply. An example would be the uncertainty linked to the effects that a new market entrant would have on the organization. The third type of uncertainty is response uncertainty, or a lack of knowledge of response alternatives and the effectiveness of these responses (Milliken, 1987). In our example, this would be the uncertainty of how to respond to the new entrant. 
Milliken (1990) measured these three dimensions of uncertainty in a survey of college administrators and found evidence for their existence as separate constructs. A number of other studies have picked up on the notion of these three separate types of perceived uncertainty. Gerloff, Muir, and Bodensteiner (1991), used factor analysis on Duncan's (1972) instrument of perceived environmental uncertainty in a survey of 118 Navy project managers, finding the instrument to reflect the three types of uncertainty, although there were some issues of reliability

on their measure of effect uncertainty (Doty et al., 2006; Gerloff et al., 1991). Based on a survey questionnaire, answered by 204 firms in New Zealand, Ashill and Jobber (2010) presented evidence suggesting the three types of uncertainty are conceptually distinct, although empirically linked. In a previous study the same authors used qualitative measures (Ashill and Jobber, 2001), and at least one study has interestingly used time series data to confirm the existence of the three uncertainty dimensions (Miller and Shamsie, 1999). However, despite the mounting evidence for the existence of these three types of uncertainty, relatively little has been done to further examine the possible relationships between the three types of uncertainty and the actual process of organizational interpretation. Although Milliken (1990) herself suggested a link between the three types of uncertainty and Daft and Weick's (1984) three-stage interpretative process, the details of this link remain largely unexplored (Ashill and Jobber, 2010; Suh et al., 2004).

\section{An Integrated Model of Interpretation and Uncertainty}

In this section, a series of propositions are developed, outlined in figure 1, about the three types of uncertainty and how they relate to the process of organizational interpretation. In keeping with Milliken's $(1987 ; 1990)$ intentions, uncertainty is linked to the 3 -stage interpretative process as 
outlined by Daft and Weick (1984). The link between scanning and perceived environmental uncertainty has received some attention in the literature, mostly with the hypothesis stated that high levels of general environmental uncertainty prompt executives and organizations to engage in higher levels of scanning (Daft and Weick, 1984; Ebrahimi, 2000; Hough and White, 2004; Lang et al., 1997; Miles and Snow, 1978; Yasai-Ardekani and Nystrom, 1996; Reus et al., 2009). Perceived general market turbulence may for instance catch the attention of executives and trigger efforts at sensemaking (Nadkarni and Barr, 2008; Neill et al., 2007). A few studies have proposed that such uncertainty by itself will not lead to scanning behavior, but that it is uncertainty combined with the strategic importance of any external issues that prompt scanning behaviors, although the empirical evidence for this is mixed (Daft et al., 1988; Elenkov, 1997). Common to these studies is that no particular distinction has been made between different types of perceived uncertainty in general (Becker and Knudsen, 2005), and the three types of environmental uncertainty identified by Milliken (1987) in particular. It remains unclear whether uncertain environmental factors by themselves prompt scanning, whether it is the interpretation of these factors that leads to scanning, or whether it is a combination of uncertainty and strategic relevance. Critically, existing studies have not provided unanimous results to support either of these views. One reason for this is that the exact definition and measurement of perceived uncertainty has varied from study to study (Suh et al., 2004). Furthermore, this uncertainty has in most studies not been broken down into separate types. Interestingly too, the cause-effect relationships reported in these studies often hinge purely on the strength of the lines of argument, not on objectively clear empirical evidence. 
Analysis of the existing literature suggests a need to distinguish clearly between general perceived environmental uncertainty, and issue-specific uncertainty. Similarly there is a need to distinguish between general and issue-specific scanning, the latter being of a more irregular type. In keeping with Milliken's $(1987,1990)$ intentions, the focus here is on issue-specific rather than general uncertainty, breaking this uncertainty down into the three types previously discussed. This paper does not theorize directly about the links between objective environmental dynamism or complexity and scanning, or about general perceived environmental uncertainty in the traditional sense.

Scanning aims to collect information and build knowledge about the environment. It has been suggested that environmental scanning absorbs uncertainty when it advances beyond the mere collection of data and begins to provide interpretations (Boulton et al., 1982; Yasai-Ardekani and Nystrom, 1996). Starting from Milliken's (1987) definition of state uncertainty as being uncertainty about the probability of general changes in state in the environment, it therefore seems logical that scanning the environment for information about a specific issue or trend will tend to lower the state uncertainty related to that particular issue (Sund, 2013). In addition to this, and as an indirect effect, the more scanning activities a given organization entertains in general, the lower one would expect the state uncertainty related to any given environmental change to be. In other words, organizational scanning, both general and specific to a particular event, leads to more certainty concerning predictions of the likelihood of particular events taking place. This is firstly because higher general scanning will increase the chance that a given event has been recognized by the organization (Sutcliffe, 1994), secondly because it will improve the basis for 
estimation of subjective probabilities and their accuracy (Becker and Knudsen, 2005). In short, if state uncertainty is the result of the absence of information about the environment (Downey and Slocum, 1975; Milliken, 1987), collecting more information should help lower uncertainty.

Proposition la: $\quad$ The more an organization scans its external environment in general, the lower will be the perceived state uncertainty related to environmental changes in general.

Proposition 1b: $\quad$ The more an organization scans its external environment in response to a particular issue or trend, the lower will be the perceived state uncertainty related to that particular trend.

Insert Figure 1 about here

Information picked up during environmental scanning typically includes more than just neutral bits of raw data. The most common external sources of information include customers and suppliers, the internet, specialized and trade publications, fairs and exhibitions, conferences, annual reports and external consultants (Haase and Franco, 2011). These sources can be both personal and impersonal. Most commonly, the information will already contain within it elements of other people or organizations' interpretations and opinions. In the worst case, the information may even be biased towards a given interpretation. For example, when a trade publication informs its readers about a particular environmental change, the expected effects of 
this change on the industry and on key players in the industry may be discussed as well. Such outside interpretations may influence or even guide any subsequent interpretations within the organization. Thus, most information is neither neutral nor un-interpreted. If effect uncertainty stems from an inability to identify cause-effect relationships and to understand whether an event will affect the organization and how deeply, it seems likely that scanning will help lower this type of uncertainty (Sund, 2013). Not only will scanning provide the organization with more data to feed the organizational sense-making, but perhaps more importantly, much of the information gathered will have been clarified (and one is tempted to say pre-interpreted) before being presented to the organization.

Proposition 2a: $\quad$ The more an organization scans its external environment in general, the lower will be the perceived effect uncertainty related to environmental changes in general.

Proposition 2b: $\quad$ The more an organization scans its external environment in response to a particular issue or trend, the lower will be the perceived effect uncertainty related to that particular trend.

The third proposition concerns the feedback loop found in figure 1 and reported by Daft \& Weick (1984). They suggest that learning might lead to further scanning in order to monitor the effects of organizational actions. If this is the case, then one could conjecture that the interpretation given to a particular event upon first identifying the event might influence subsequent scanning related to that particular event. For example, Daft, Sormunen, and Parks (1988) noted that uncertainty by itself will not lead to scanning behavior since managers may not 
be interested in events unless these are perceived as strategically important. Hence the perceived importance of an event may prompt further scanning (Boyd and Fulk, 1996). Flores, Zheng, Rau and Thomas (2012) take this argument one step further, suggesting that organizational interpretations in fact act in the same way as individual cognitive filters, limiting the amount and type of data acquired and distributed within the organization, i.e. directing and constraining scanning. This constrained scanning is of an irregular type, being a direct reaction to the given event (Fahey and King, 1977). The environment is scanned for specific data concerning that event, and other data is filtered out. The bigger the predicted impact of that event, whether negative or positive, the more likely that the organization will engage in more directed scanning to help form or perfect the interpretation. Any significant threat or opportunity is likely to act as a trigger for such targeted, issue-specific, and irregular scanning.

Proposition 3: $\quad$ The higher the predicted impact of a given event and regardless of the uncertainty related to that prediction, the higher will be the interest in the event and the more likely will it be that scanning activity will be undertaken in the related area of the environment.

A number of studies have shown that aside from lowering state and effect uncertainties, scanning affects interpretation, in particular threat/opportunity categorizations, in terms of: (1) an evaluation of the event in negative or positive terms, (2) an estimation of potential losses or gains as a result of the event, and (3) a consideration of the controllability by the organization (Jackson and Dutton, 1988; Thomas et al., 1993; Thomas and McDaniel, 1990). The greater the amount, and the completeness of information available to decision makers; the greater the likelihood that 
they will sense that they master the situation and thus perceive any changes as controllable (Eisenhardt, 1989; Thomas et al., 1993). The fact that scanning enhances the early detection of events before threat interpretations can emerge should further contribute to increasing the sense of control (Jackson and Dutton, 1988). The proposition made in this paper is thus that there is value in general environmental scanning, not just because this can raise the interpretation or absorptive capacity of the organization (Dane, 2013; Danneels, 2008), but because it will affect the sense of control (Sund, 2013). As previously pointed out, much of the information collected by the organization during scanning will contain elements of interpretations, helping managers to identify cause-effect relationships and enhancing their sense of shared understanding of the environment.

Proposition 4: $\quad$ Organizations that engage in more general external scanning will tend to interpret any given noticed event as more controllable.

Effect uncertainty measures on the one hand uncertainty related to whether a given event will affect the organization and on the other hand uncertainty linked to the predicted magnitude of this impact (Milliken, 1987). This uncertainty accompanies the actual interpretation and categorization of an event. It has been suggested in the literature that effect uncertainty may arise from the inability to assess how customers, competitors and other actors might influence the organization (Miller and Shamsie, 1996). This can be because the organization may be lacking the necessary skills, information and resources to correctly understand the effects of environmental changes (Miller and Shamsie, 1999). It is not clear whether this type of 
uncertainty influences the actual interpretation or threat/opportunity categorization itself, or that it is a consequence of that interpretation, but rather it influences the time spent interpreting. As Milliken (1987) noted:

"It seems likely that if administrators are uncertain about the effect of an environmental change or changes, they may spend a lot more time (and use many resources) in the "environmental threat and opportunity analysis phase" of strategic planning... Uncertainty could paralyze the strategic planning process as administrators argue about whether and how significantly their organization is likely to be affected by various environmental changes."

Milliken (1987: 140)

This would suggest that if effect uncertainty has an effect on the interpretation process other than extending the time spent analyzing, this effect might be on the response rather than the interpretation. The only paper identified dealing directly with the influence of effect uncertainty on the interpretation process is that of Miller and Shamsie (1999), who found that firms experiencing high effect uncertainty will tend to have less varied product lines. Their argument was that effect uncertainty would discourage managers from straying into expensive product variations. Product variation and new product launch is clearly one type of strategic decision or action open to organizations facing changing environments. As a result of the above analysis it seems reasonable to propose more generally that higher effect uncertainty will make it more difficult for an organization to determine whether a response is warranted. Therefore, higher effect uncertainty will be associated with less organizational action. 
Uncertainty is reduced with information and therefore changes over the course of the interpretation of a given issue (Weick, 1995). As state and effect uncertainty are reduced, and opportunity/threat interpretations are formed, ultimately the organization is left only with risk rather than uncertainty, and can therefore make an informed decision regarding responses.

Proposition 5: $\quad$ A higher effect uncertainty will lead to a delay in actions being taken.

Issue interpretation plays an important role in shaping strategic responses (Ginsberg and Venkatraman, 1995). Within the body of literature on the knowledge-based view of the firm, for example, it has been shown that various interpretation mechanisms may benefit the subsequent level of knowledge application (Song et al., 2005). Few studies, however, have fully explored the effects of the popular threat/opportunity interpretation on response (Julian and Ofori-Dankwa, 2008). Thomas, Clark and Gioia (1993) found that the positive and gain items are indistinguishable and hypothesized that an interpretation in high positive-gain terms will lead to a greater response, although they did not find empirical support for this hypothesis. A number of studies have proposed to measure threat and opportunity separately, in case these labels have separate connotations (Denison et al., 1996; Jackson and Dutton, 1988; Julian and OforiDankwa, 2008). Julian and Ofori-Dankwa (2008), for example, separated threat and opportunity and found both of these constructs to be positively correlated to intended responses in the case of external environmental change. Plambeck (2012) found that while both positive and negative 
interpretations will lead to responses, negative interpretations will lead to less innovative product responses than positive ones.

The evidence thus suggests that more generally, if an issue is seen as an important opportunity or threat, the organization will be more likely to investigate potential responses. It seems reasonable to assume that the interpretation given to a certain event will affect the magnitude of the organizational response to this event. I thus posit here that an interpretation in high positive-gain terms or in high negative/loss terms is likely to result in higher levels of response.

Proposition 6a: $\quad$ The interpretation of a given event in high positive-gain or negative-loss terms will lead to more actions being taken.

The effect of controllability on response has been examined in at least one previous study, with somewhat mixed results. Julian and Ofori-Dankwa (2008) report a marginal, but non-significant, positive relationship between influence and external response, whilst reporting a strong positive relationship between manageability and response in a separate study (Julian et al., 2008). Although the use of these different labels for control may signal somewhat different underlying constructs, given the evidence, it can reasonably be posited that controllability, when defined as whether the organization has the capabilities act, and a choice over whether or not to act (Jackson and Dutton, 1988; Thomas et al., 1993; Thomas and McDaniel, 1990), will lead the organization to adopt larger responses. 
Proposition 6b: $\quad$ The interpretation of a given event as controllable will lead to more actions being taken.

Finally proposition seven concerns the effect of response uncertainty on organizational action. This relationship has benefited from much analysis beyond the simple identification and validation of the response uncertainty construct (Milliken, 1990). Milliken (1987) suggested that high levels of response uncertainty may have the effect of delaying strategy implementation as response alternatives are developed and analyzed. The more uncertain the top managers of an organization feel about the potential effectiveness of a set of organizational actions, the less likely they will be to adopt those actions, preferring to continue scanning and collectively interpreting data about the event until a suitable course of action can be found for which the corresponding uncertainty is sufficiently low. Information in this context can help the organization determine what outcomes will follow from various possible lines of action (Weick, 1995) and scanning thus can be resorted to at every step of the interpretation process. Response uncertainty, or the lack of knowledge of response alternatives and the effectiveness of these responses, acts as a trigger to encourage further rounds of information seeking and interpretation by managers, whilst postponing actual organizational responses. McKelvie, Haynie and Gustavsson's (2011) study of entrepreneurial software firms, in which they concluded that response uncertainty will represent an impediment to entrepreneurial action, seems to support this notion. 
Proposition 7: $\quad$ Greater response uncertainty will lead to less responsive actions being taken.

\section{Discussion and Potential for Further Research}

Whether referred to as an organization's information processing capacity (Kuvaas, 2002), sensemaking capability (Weick, 1995), or absorptive capacity (Berghman et al., 2013; Zahra and George, 2002), the ability of an organization to make sense of and react to environmental signals is recognized as important to the success of an organization. The field of managerial and organizational cognition thus continues to be promising in terms of helping us understand decision making and organizational performance differences, as well as generally improving the theory of the firm (Kaplan, 2011; Walsh, 1995). Interpretive theory and the closely associated concept of perceived environmental uncertainty also remain highly popular in the management literature in general. However, studies using the perceived uncertainty construct in particular continue to suffer from conflicting empirical results and very few studies have examined how different types of uncertainty accompany, influence and are influenced by different stages of the organizational interpretation process in a holistic fashion. This paper fills the gap by offering a series of testable propositions, some of them entirely novel, regarding links between scanning, interpretation, organizational responses and three types of perceived uncertainty.

One implication of the proposed model developed in this paper and outlined in figure 1, is that there are still research opportunities for studies in the field of organizational cognition to (1) distinguish clearly between objective uncertainty, general perceived environmental uncertainty, 
and issue-specific uncertainty; (2) take into account the growing evidence that issue-specific perceived uncertainty may take a variety of forms and accompany various stages of the organizational process of environmental interpretation; and (3) distinguish between general (regular) scanning, and issue-specific (irregular) scanning when testing relationships within this process. Studies of organizational cognition, and in particular those using the perceived uncertainty construct, can benefit from adopting and emphasizing such distinctions, which open up new research questions to be explored. To illustrate this point, consider just one set of relationships within the organizational interpretation process: that between scanning and uncertainty, and how this relationship depends on the definition of uncertainty.

When uncertainty is defined as an objective characteristic of the environment, it is typically measured by examining archival data sets on rates of change in environmental variables or munificence, i.e. the volatility and complexity of the environment (Bourgeois, 1985). Environmental variables measured thus include, for example, variability of industry sales and profit levels over time. Rapidly changing (sometimes called high-velocity) environments are thought to pose a particular challenge to organizations, as decision-making needs to be rapid as well (Eisenhardt, 1989). Whilst a rapidly changing (objectively uncertain) environment might not directly lead to scanning, it will certainly influence the perceived (subjective) environmental uncertainty about the environment (Daft et al, 1988). However, beyond this very general picture we know little about the details of this process. Whilst it may be true that organizations devise general mechanisms for the regular, routine scanning of the environment in response to general perceived uncertainty, a large proportion of scanning is likely to be directed at specific 
environmental issues and be of a more irregular and reactive type. This begs a host of potential research questions. What are the determinants of the amount of time spent by executives on regular versus irregular scanning and what is the role of general, state and effect uncertainties in this context? Are the chosen sources of information related to specific issue characteristics, or to organizational characteristics? How do issue interpretations influence these choices? Such questions can meaningfully be explored by adopting more precise definitions of uncertainty and by recognizing that uncertainty may be linked to the general environment, but also to specific issues of strategic importance, and that these are not the same thing.

\section{Conclusion}

Milliken's $(1987,1990)$ identification of three separate types of perceived environmental uncertainty sought to bring some structure to a growing body of literature and perhaps to explain some of the failures of scholars to reproduce results. Although various stages and labels of interpretation have been empirically linked between themselves and with various definitions of uncertainty, the evidence remains scattered across the literature and is incomplete. When brought together, the contributions of Daft and Weick (1984) and Milliken (1987, 1990) strengthen our understanding of organizational cognition and may help explain some of the conflicting empirical evidence on interpretation and uncertainty amassed over the past three decades. However, no study has focused on further developing and integrating existing findings and propositions so far. This paper has attempted precisely that, proposing a fuller account of the interactions between organizational interpretation and three types of issue-specific uncertainty. 
Further empirical research is needed to continue validating the various constructs and measures discussed, as well as the relationships between these, as outlined in this paper. The interpretation process and perceived uncertainty constructs continue to be explored within fields as diverse as information systems, human resource management, strategy, marketing and organizational behavior, and all of these fields can validly gain from applying these constructs within their own domains and can further add to our understanding of cognition and uncertainty.

\section{Acknowledgements}

The author wishes to thank the two anonymous reviewers at IJOA for valuable feedback in the development of this paper, as well as the editor Prof. Peter Stokes. This paper has been developed from a paper presented at the British Academy of Management conference held in Sheffield, UK in September 2010, where it was awarded best paper in the Strategic Foresight track. 


\section{References}

Anderson, M. H. (2008). Social networks and the cognitive motivation to realize network opportunities: a study of managers' information gathering behaviors. Journal of Organizational Behavior, 29(1).

Anderson, M. H., \& Nichols, M. L. (2007). Information gathering and changes in threat and opportunity perceptions. Journal of Management Studies, 44(3), 367-387.

Ashill, N. J., \& Jobber, D. (2001). Defining the Domain of Perceived Environmental Uncertainty: An Exploratory Study of Senior Marketing Executives. Journal of Marketing Management, 17(5/6), 543.

Ashill, N. J., \& Jobber, D. (2010). Measuring State, Effect, and Response Uncertainty: Theoretical Construct Development and Empirical Validation. Journal of Management, 36(5), 1278-1308.

Barr, P. S. (1998). Adapting to Unfamiliar Environmental Events: A Look at the Evolution of Interpretation and Its Role in Strategic Change. Organization Science, 9(6), 644-669.

Beal, R. M. (2000). Competing effectively: Environmental scanning, competitive strategy, and organizational performance in small manufacturing firms. Journal of Small Business Management, 38(1), 27-47.

Becker, M. C., \& Knudsen, T. (2005). The role of routines in reducing pervasive uncertainty. Journal of Business Research, 58(6), 746-757.

Berghman, L., Matthyssens, P., Streukens, S., \& Vandenbempt, K. (2013). Deliberate Learning Mechanisms for Stimulating Strategic Innovation Capacity. Long Range Planning, 46(12), 39-71.

Boulton, W. R., Lindsay, W. M., Franklin, S. G., \& Rue, L. W. (1982). Strategic Planning: Determining the Impact of Environmental Characteristics and Uncertainty. The Academy of Management Journal, 25(3), 500-509.

Bourgeois, L. J. (1985). Strategic Goals, Perceived Uncertainty, and Economic-Performance in Volatile Environments. Academy of Management Journal, 28(3), 548-573. 
Boyd, B. K., Dess, G. G., \& Rasheed, A. M. A. (1993). Divergence between Archival and Perceptual Measures of the Environment - Causes and Consequences. Academy of Management Review, 18(2), 204-226.

Boyd, B. K., \& Fulk, J. (1996). Executive scanning and perceived uncertainty: A multidimensional model. Journal of Management, 22(1), 1-21.

Buchko, A. A. (1994). Conceptualization and Measurement of Environmental Uncertainty - an Assessment of the Miles and Snow Perceived Environmental Uncertainty Scale. Academy of Management Journal, 37(2), 410-425.

Citrin, A. V., Lee, R. P., \& McCullough, J. (2007). Information use and new product outcomes: The contingent role of strategy type. Journal of Product Innovation Management, 24(3), 259-273.

Daft, R. L., Sormunen, J., \& Parks, D. (1988). Chief Executive Scanning, Environmental Characteristics, and Company Performance: An Empirical Study. Strategic Management Journal, 9(2), 123-139.

Daft, R. L., \& Weick, K. E. (1984). Toward a Model of Organizations as Interpretation Systems. Academy of Management Review, 9(2), 284-295.

Dane, E. (2013). Things Seen and Unseen: Investigating Experience-Based Qualities of Attention in a Dynamic Work Setting. Organization Studies, 34(1), 45-78.

Danneels, E. (2008). Organizational Antecedents of Second-Order Competences. Strategic Management Journal, 29(5), 519-543.

Denison, D. R., Dutton, J. E., Kahn, J. A., \& Hart, S. L. (1996). Organizational Context and the Interpretation of Strategic Issues: A Note On CEOs' Interpretations of Foreign Investment. Journal of Management Studies, 33(4), 453-474.

Doty, D. H., Bhattacharya, M., Wheatley, K. K., \& Sutcliffe, K. M. (2006). Divergence between informant and archival measures of the environment: Real differences, artifact, or perceptual error? Journal of Business Research, 59(2), 268-277.

Downey, H. K., Hellriegel, D., \& Slocum, J. W. (1975). Environmental Uncertainty - Construct and Its Application. Administrative Science Quarterly, 20(4), 613-629.

Downey, H. K., \& Slocum, J. W. (1975). Uncertainty: Measures, Research, and Sources of Variation. The Academy of Management Journal, 18(3), 562-578. 
Duncan, R. B. (1972). Characteristics of Organizational Environments and Perceived Environmental Uncertainty. Administrative Science Quarterly, 17(3), 313-327.

Dutton, J. E., \& Duncan, R. B. (1987). The Creation of Momentum for Change Through the Process of Strategic Issue Diagnosis. Strategic Management Journal, 8(3), 279-295.

Ebrahimi, B. P. (2000). Perceived strategic uncertainty and environmental scanning behavior of Hong Kong Chinese executives. Journal of Business Research, 49(1), 67-77.

Eisenhardt, K. M. (1989). Making Fast Strategic Decisions in High-Velocity Environments. The Academy of Management Journal, 32(3), 543-576.

Elenkov, D. S. (1997). Strategic uncertainty and environmental scanning: The case for institutional influences on scanning behavior. Strategic Management Journal, 18(4), 287302.

Fahey, L., \& King, W. R. (1977). Environmental Scanning for Corporate-Planning. Business Horizons, 20(4), 61-71.

Flores, L. G., Zheng, W., Rau, D., \& Thomas, C. H. (2012). Organizational Learning: Subprocess Identification, Construct Validation, and an Empirical Test of Cultural Antecedents. Journal of Management, 38(2), 640-667.

Galbraith, J. (1974). Organization Design: An Information Processing View. Interfaces, 4, 28-36.

Garg, V. K., Walters, B. A., \& Priem, R. L. (2003). Chief executive scanning emphases, environmental dynamism, and manufacturing firm performance. Strategic Management Journal, 24(8), 725-744.

Garud, R., Dunbar, R. L. M., \& Bartel, C. A. (2011). Dealing with Unusual Experiences: A Narrative Perspective on Organizational Learning. Organization Science, 22(3), 587-601.

Gerloff, E. A., Muir, N. K., \& Bodensteiner, W. D. (1991). 3 Components of Perceived Environmental Uncertainty - an Exploratory Analysis of the Effects of Aggregation. Journal of Management, 17(4), 749-768.

Ginsberg, A. (1988). Measuring and Modelling Changes in Strategy: Theoretical Foundations and Empirical Directions. Strategic Management Journal, 9(6), 559-575.

Ginsberg, A. (1989). Construing the Business Portfolio: A Cognitive Model Of Diversification. Journal of Management Studies, 26(4), 417-438. 
Ginsberg, A., \& Venkatraman, N. (1995). Institutional Initiatives for Technological Change: From Issue Interpretation to Strategic Choice. Organization Studies, 16(3), 425-448.

Haase, H. \& Franco, M. (2011) Information Sources for Environmental Scanning: do Industry and firm size matter? Management Decision, 49(10), 1642-1657.

Hambrick, D. C. (1982). Environmental Scanning and Organizational Strategy. Strategic Management Journal, 3(2), 159-174.

Harris, S. G. (1994). Organizational culture and individual sensemaking: a schema-based perspective. Organization Science, 5(3), 309-321.

Hough, J. R. \& White, M. A. (2004) Scanning actions and environmental dynamism: Gathering information for strategic decision making. Management Decision, 42(6), 781 - 793.

Huber, G. P. (1991). Organizational Learning: The Contributing Processes and the Literatures. Organization Science, 2(1), 88-115.

Huber, G. P., \& Daft, R. L. (1987). The Information Environments of Organizations. In K. Roberts \& L. Porter (Eds.), Handbook of Organization Communication. Beverly Hills, CA: Sage.

Jackson, S. E., \& Dutton, J. E. (1988). Discerning Threats and Opportunities. Administrative Science Quarterly, 33(3), 370-387.

Julian, S. D., \& Ofori-Dankwa, J. C. (2008). Toward an integrative cartography of two strategic issue diagnosis frameworks. Strategic Management Journal, 29(1), 93-114.

Julian, S. D., Ofori-Dankwa, J. C., \& Justis, R. T. (2008). Understanding strategic responses to interest group pressures. Strategic Management Journal, 29(9), 963-984.

Kaplan, S. (2011). Research in cognition and strategy: reflections on two decades of progress and a look to the future. Journal of Management Studies, 48(3), 665-695.

Kreiser, P. \& Marino, L. (2002) Analyzing the historical development of the environmental uncertainty construct. Management Decision, 40(9), 895 - 905.

Kuvaas, B. (2002). An exploration of two competing perspectives on informational contexts in top management strategic issue interpretation. Journal of Management Studies, 39(7), 977-1001. 
Lang, J. R., Calantone, R. J., \& Gudmundson, D. (1997). Small firm information seeking as a response to environmental threats and opportunities. Journal of Small Business Management, 35(1), 11-23.

Lawrence, P. R., \& Lorsch, J. W. (1967). Organization and environment managing differentiation and integration. Boston: Harvard Business School Press.

Lichtenthaler, U. (2009) Absorptive Capacity, Environmental Turbulence, and the Complementarity of Organizational Learning Processes. Academy of Management Journal, 52(4), 822-846.

Marcel, J. J., Barr, P. S., \& Duhaime, I. M. (2010). The Influence of Executive Cognition on Competitive Dynamics. Strategic Management Journal, 32(2), 115-138.

McCall, M. W., \& Kaplan, R. E. (1985). Whatever it takes : decision makers at work. Englewood Cliffs, N.J.: Prentice-Hall.

McKelvie, A., Haynie, J. M., \& Gustavsson, V. (2011). Unpacking the uncertainty construct: Implications for entrepreneurial action. Journal of Business Venturing, 26(3), 273-292.

Miles, R. E., \& Snow, C. C. (1978). Organizational strategy, structure, and process (International student edition ed.). Tokyo: McGraw-Hill Kogakusha.

Miller, D., \& Shamsie, J. (1996). The Resource-Based View of the Firm in Two Environments: The Hollywood Film Studios From 1936 to 1965. Academy of Management Journal, 39(3), 519-543.

Miller, D., \& Shamsie, J. (1999). Strategic responses to three kinds of uncertainty: Product line simplicity at the Hollywood film studios. Journal of Management, 25(1), 97-116.

Milliken, F. J. (1987). 3 Types of Perceived Uncertainty About the Environment - State, Effect, and Response Uncertainty. Academy of Management Review, 12(1), 133-143.

Milliken, F. J. (1990). Perceiving and Interpreting Environmental-Change - an Examination of College Administrators Interpretation of Changing Demographics. Academy of Management Journal, 33(1), 42-63.

Nag, R., \& Gioia, D. (2012). From common to uncommon knowledge: Foundations of firmspecific use of knowledge as a resource, Academy of Management Journal, 55(2), 421457. 
Nadkarni, S., \& Barr, P. S. (2008). Environmental context, managerial cognition, and strategic action: an integrated view. Strategic Management Journal, 29(13).

Neill, S., McKee, D., \& Rose, G. M. (2007). Developing the organization's sensemaking capability: Precursor to an adaptive strategic marketing response. Industrial Marketing Management, 36(6), 731-744.

Pandza, K., \& Thorpe, R. (2009). Creative Search and Strategic Sense-making: Missing Dimensions in the Concept of Dynamic Capabilities. British Journal of Management, 20, 118-131.

Plambeck, N. (2012). The development of new products: The role of firm context and managerial cognition. Journal of Business Venturing, 27(6), 607-621.

Qiu, T. (2008). Scanning for competitive intelligence: a managerial perspective. European Journal of Marketing, 42(7/8), 814-835.

Reus, T., Ranft, A., Lamont, B. \& Adams, G. (2009) An Interpretive Systems View of Knowledge Investments. Academy of Management Review, 34(3), 382-400.

Song, M., van der Bij, H., \& Weggeman, M. (2005). Determinants of the Level of Knowledge Application: A Knowledge-Based and Information-Processing Perspective. Journal of Product Innovation Management, 22(5), 430-444.

Starbuck, W. H., \& Milliken, F. J. (1988). Executives' Perceptual Filters: What They Notice and How They Make Sense. In D. Hambrick (Ed.), The Executive Effect: Concepts and Methods for Studying Top Managers (pp. 35-66). Greenwich, CT: JAI Press.

Suh, W. S., Key, S. K. \& Munchus, G. (2004) Scanning Behavior and Strategic Uncertainty: Proposing a New Relationship by Adopting New Measurement Constructs. Management Decision, 42(8), 1001 - 1016.

Sund, K. J. (2013). Scanning, Perceived Uncertainty, and the Interpretation of Trends: A Study of Hotel Directors' Interpretation of Demographic Change. International Journal of Hospitality Management, 33(1), 294-303.

Sutcliffe, K. M. (1994). What Executives Notice - Accurate Perceptions in Top Management Teams. Academy of Management Journal, 37(5), 1360-1378. 
Thomas, J. B., Clark, S. M., \& Gioia, D. A. (1993). Strategic Sensemaking and Organizational Performance - Linkages among Scanning, Interpretation, Action, and Outcomes. Academy of Management Journal, 36(2), 239-270.

Thomas, J. B., \& McDaniel, R. R., Jr. (1990). Interpreting Strategic Issues: Effects of Strategy and the Information-Processing Structure of Top Management Teams. The Academy of Management Journal, 33(2), 286-306.

Tosi, H., Aldag, R., \& Storey, R. (1973). Measurement of Environment - Assessment of Lawrence and Lorsch Environmental Uncertainty Subscale. Administrative Science Quarterly, 18(1), 27-36.

Walsh, J. P. (1995). Managerial and Organizational Cognition: Notes from a Trip Down Memory Lane. Organization Science, 6(3), 280-321.

Weick, K. E. (1995) Sensemaking in Organizations, Thousands Oaks CA: Sage.

Weick, K. E. (2002). Puzzles in Organizational Learning: An Exercise in Disciplined Imagination. British Journal of Management, 13, S7.

Weick, K. E., Sutcliffe, K. M., \& Obstfeld, D. (2005). Organizing and the process of sensemaking. Organization Science, 2005, 409-421.

Yasai-Ardekani, M., \& Nystrom, P. C. (1996). Designs for environmental scanning systems: Tests of a contingency theory. Management Science, 42(2), 187-204.

Zahra, S. \& George, G. (2002) absorptive capacity: a review, reconceptualization, and extension. Academy of Management Review, 27(2), 185-203. 


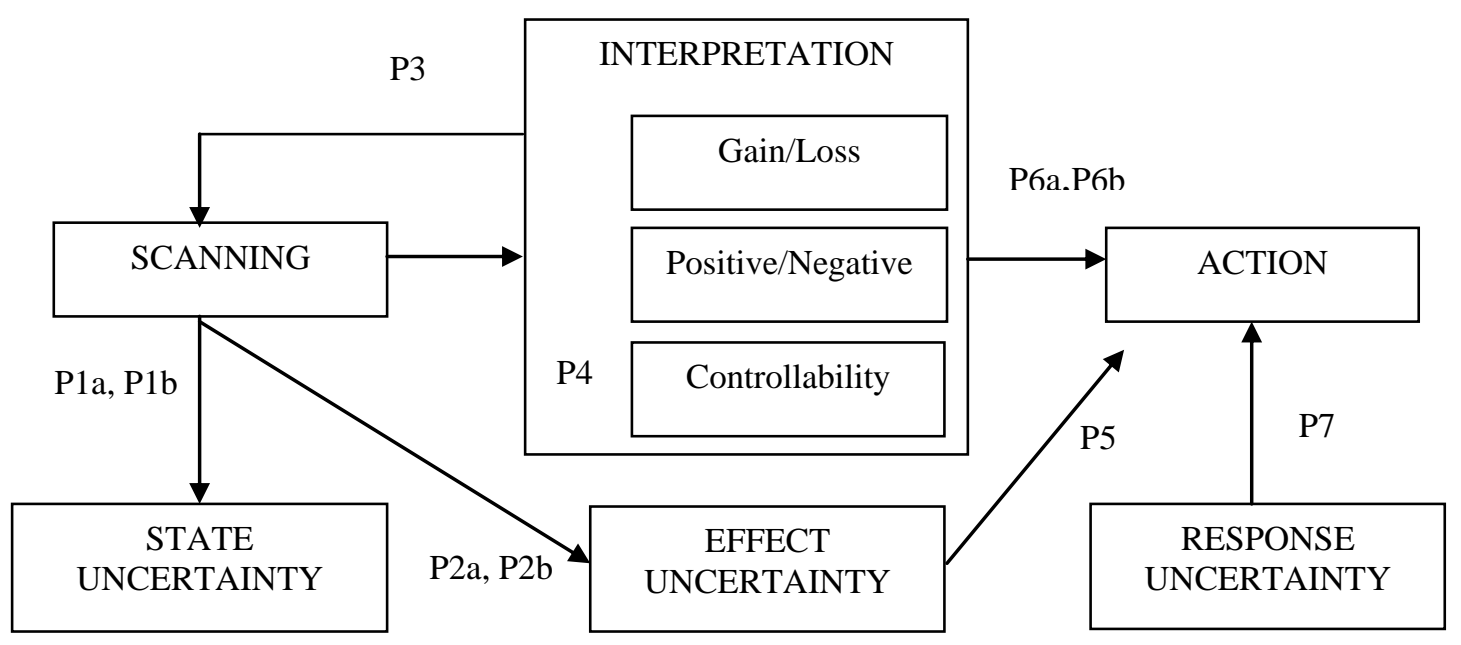

FIGURE 1

Propositions 